\title{
Effect of walking on circadian rhythms and sleep quality of patients with lung cancer: a randomised controlled trial
}

\author{
Hui-Mei Chen ${ }^{1,2}$, Chun-Ming Tsai ${ }^{3,4}$, Yu-Chung Wu ${ }^{4,5}$, Kuan-Chia Lin ${ }^{6}$ and Chia-Chin Lin ${ }^{\star, 2}$ \\ ${ }^{1}$ School of Nursing, College of Nursing, National Taipei University of Nursing and Health Sciences, Taipei, Taiwan; ${ }^{2}$ School of \\ Nursing, College of Nursing, Taipei Medical University, Taipei, Taiwan; ${ }^{3}$ Chest Department, Taipei Veterans General Hospital, \\ Taipei, Taiwan; ${ }^{4}$ School of Medicine, National Yang-Ming University, Taipei, Taiwan; ${ }^{5}$ Division of Thoracic Surgery, Department of \\ Surgery, Taipei Veterans General Hospital, Taipei, Taiwan and ${ }^{\circ}$ Institute of Hospital and Health Care Administration, Community \\ Medicine Research Center, National Yang-Ming University, Taipei, Taiwan
}

Background: Sleep disturbances and poor rest-activity rhythms, which can reduce the quality of life, are highly prevalent among patients with lung cancer.

Methods: This trial investigated the effects of a 12-week exercise intervention including home-based walking exercise training and weekly exercise counseling on 111 lung cancer patients. Participants were randomly allocated to receive the intervention or usual-care. Outcomes included objective sleep (total sleep time, TST; sleep efficiency, SE; sleep onset latency, SOL; and wake after sleep onset, WASO), subjective sleep (Pittsburgh Sleep Quality Index, PSOI), and rest-activity rhythms (r24 and I<O). Outcomes were assessed at baseline and 3 and 6 months after intervention.

Results: The PSQI (Wald $\chi^{2}=15.16, P=0.001$ ) and TST (Wald $\chi^{2}=7.59, P=0.023$ ) of the patients in the exercise group significantly improved 3 and 6 months after intervention. The moderating effect of $\mathrm{I}<\mathrm{O}$ on TST was significant ( $\beta$ of group $\times \mathrm{I}<\mathrm{O}=3.70$, $P=0.032)$.

Conclusions: The walking program is an effective intervention for improving the subjective and objective sleep quality of lung cancer patients and can be considered an optional component of lung cancer rehabilitation.

Lung cancer is the leading cause of cancer deaths in Taiwan (Ministry of Health and Welfare, 2013) and worldwide (Siegel et al, 2013). Patients with lung cancer often experience sleep disturbances during and after treatment (Chen et al, 2008) with a prevalence of $45-57 \%$ (Gooneratne et al, 2007; Chen et al, 2008). Sleep disturbances can affect the quality of life (Gooneratne et al, 2007) and even the prognosis (Wang et al, 2008) of patients with lung cancer as well as disrupt their rest-activity rhythms (Levin et al, 2005). In general, sleep quality is subjectively assessed using the Pittsburgh Sleep Quality Index (PSQI), in which a score of $>5$ indicates poor sleep quality (Buysse et al, 1989). Furthermore, sleep quality can be objectively assessed through actigraphy: sleep disturbance is indicated by a total sleep time (TST) of $\leqslant 6.5 \mathrm{~h}$ (Lacks and Morin, 1992), sleep efficiency (SE) of $\leqslant 85 \%$ (Coates et al, 1982), sleep onset latency (SOL) of $>30 \mathrm{~min}$ (Espie et al, 2001), or wake after sleep onset (WASO) of $>30 \mathrm{~min}$ (Savard and Morin, 2001). Factors including age (Kim et al, 2000; Chen et al, 2015b), sex, marital status (Baiden et al, 2015), cancer stage, and anticancer treatments (Roscoe et al, 2007; Chen et al, 2015b), which can affect sleep quality, must be included in sleep quality assessments for cancer patients. Unstable rest-activity rhythms lead to sleep disturbance (Miaskowski and Lee, 1999; Berger et al, 2007), and non-small-cell lung cancer patients with disrupted restactivity rhythms may experience poor sleep quality and insomnia (Levin et al, 2005).

*Correspondence: Dr C-C Lin; E-mail: clin@tmu.edu.tw

Received 22 March 2016; revised 21 September 2016; accepted 28 September 2016; published online 3 November 2016

(c) 2016 Cancer Research UK. All rights reserved 0007-0920/16 
A cross-sectional study, using actigraphy to measure objective sleep quality and assess rest-activity rhythms in patients with lung cancer, reported more favorable TST, SE, SOL, 24-h autocorrelation coefficient (r24), and in-bed less than out-of-bed dichotomy index $(\mathrm{I}<\mathrm{O})$ data in patients performing light physical activities for at least $295 \mathrm{~min} /$ day than in those performing these activities for $<295 \mathrm{~min} /$ day (Chen et al, 2015b). In addition, $\mathrm{I}<\mathrm{O}$ is a predictor of TST and SOL (Chen et al, 2015b). These results indicate a strong correlation among physical activity, sleep quality, and rest-activity rhythms. Thus, exercise may stabilise rest-activity rhythms and improve sleep quality (Coleman et al, 2012).

Few studies-most with small sample sizes-have reported the positive effects of exercise on rest-activity rhythms. Furthermore, providing healthy adults with an exercise regimen can improve their sleep-wake cycle (Yamanaka et al, 2010). Some exercise intervention studies have reported that exercise can improve the sleep quality of patients with lung or colorectal cancer (Cheville et al, 2012), breast cancer, and other cancer types (YoungMcCaughan et al, 2003; Rabin et al, 2009). However, other studies have found that exercise improves the subjective but not objective sleep quality of patients with cancer (Young-McCaughan et al, 2003). Thus, the effects of exercise on sleep disturbances in patients with cancer remain unclear, possibly because of the inconsistency among previous studies regarding the type, intensity, frequency, and duration of exercise regimens and the diversity of assessment methods used.

This study investigated (1) the effect of a 12-week walking exercise program in improving subjective and objective sleep quality and stabilising rest-activity rhythms and (2) the moderating effect of rest-activity rhythms on subjective and objective sleep quality among patients with lung cancer.

\section{MATERIALS AND METHODS}

Study design and participants. The present research is a substudy of a larger research project; some of the findings have been published previously (Chen et al, 2015a). This was a randomised controlled trial, comprising a walking exercise group that received a 12-week regimen of home-based walking exercises and another group that received usual-care. Data were collected using a questionnaire, and the measurements of restactivity rhythms and sleep quality were collected at three time points [pretrial (T1), after 3 months (T2), and after 6 months (T3)]. This study was approved by the Taipei Veterans General Hospital's Institutional Review Board, and consent was obtained from all participants.

Participants were recruited from a medical center in Northern Taiwan. Patients with lung cancer who were aged $\geqslant 18$ years, could communicate in either Mandarin or Taiwanese, and were not cognitively impaired were included. By contrast, those performing regular exercise, having congestive heart failure, or having orthopedic disorders of the lower limbs were excluded.

Procedure. Patients who visited the pulmonary medicine or thoracic surgery outpatient department and agreed to participate in this study were referred to the researchers. After the patients signed the consent form, we instructed them on how to complete the T1 questionnaire, comprising a survey of demographic data, the PSQI questionnaire, a sleep diary, and a 3-day physical activity record. Participants were provided actigraphs to be worn on their nondominant arm and then asked to take home the physical activity record questionnaire and record their physical activities. Finally, participants were provided a shockproof envelope for returning the actigraph and physical activity record, through registered mail. After completing the initial steps, by using computer-randomised group assignment, we determined assigned participants to walking exercise or the usualcare. Follow-up data 3 (T2) and 6 (T3) months after intervention were collected using the questionnaires and actigraphs (please see the 'Supplementary Material A: Study calendar' for the details).

Interventions. A 12-week regimen of home-based walking exercises, comprising walking at a moderate intensity for $40 \mathrm{~min}$, three times a week, was administered along with weekly exercise counseling. After collecting pretrial measurements, we explained the participants how to perform the exercises, according to an instruction manual for the exercise regimen. The detailed instructions, provided at the hospital clinics, included the determination of activity intensity, demonstration of pulse measurement, criteria for scores of 6-20 on the Borg's rating of perceived exertion (RPE; Borg, 1998), prevention of exerciserelated injuries, and conditions necessitating termination of an exercise session. Participants were instructed that the exercises would be effective only if they reached $60-80 \%$ of the target heart rate, as determined by the Karvonen method (Karvonen et al, 1957), and 13-15 on the RPE.

For each participant, we discussed exercise regimen-related issues weekly through the telephone. For instance, we discussed whether participants' exercise fulfilled the prescribed intensity, duration, or frequency and whether the participants experienced any adverse effects. If a patient had not exercised for $\geqslant 3$ days and we determined that this lack of exercise was not due to adverse effects of exercising, we reiterated the exercise instructions and encouraged the patient to continue the regimen. The participants were reminded to record their activity after every session and were instructed that after completing the regimen in 3 months, we would collect the record of physical activities for calculating the regimen completion rates (Please see the 'Supplementary Material B: Instructions for the home-based walking exercise program' for details).

The usual-care group. The usual care group was provided services similar to those provided to the walking exercise group depending on their treatment (e.g., postoperative care, chemotherapy care, and outpatient department follow-up), except for the 12-week regimen of home-based walking exercise training and weekly telephone exercise counseling. The patients were asked to maintain normal daily activity and not perform additional exercise during the study period. For ethical considerations, we mailed the exercise booklet to the participants and offered exercise counseling at the end of the study.

\section{Measures}

Subjective sleep quality. We used PSQI (Buysse et al, 1989), comprising 19 items, with each score ranging from 0 to 3 and a total score range of $0-21$. A score of 0 indicated no sleep problems and 3 indicated serious sleep problems. Because of its widespread use, PSQI has been translated into a Taiwanese version (PSQI-T). The reliability of PSQI-T-measured using Cronbach's $\alpha$-is 0.79 , and the test-retest reliability-measured using 16 patients who took a retest $20-28$ days later-is 0.91 (Tzeng et al, 2012).

Objective sleep quality. An actigraph (Ambulatory Monitoring, Ardsley, NY, USA) was worn on patients' nondominant arms to collect data continuously for $72 \mathrm{~h}$. Sleep parameters included TST, SE, SOL, and WASO. The Micro-Mini Actigraph and the Action W2 analysis software have high validity, with an internal consistency of $91 \%$ for minute-by-minute synchronised measurements using polysomnography (de Souza et al, 2003). Using the zero cross mode to sample patient data at 1-min epoch intervals is sufficient for analyzing a patient's sleep and activities for 3 
consecutive days (Littner et al, 2003). The Act Millennium software (Ambulatory Monitoring) was first used to download the data from the actigraph. Subsequently, the Action W2 software was used to process and calculate parameters, including TST, SE, SOL, and WASO (Coates et al, 1982; Lacks and Morin, 1992; Espie et al, 2001; Savard and Morin, 2001), by using the ColeKripke algorithm (de Souza et al, 2003). Patients' sleep diaries were used to corroborate bedtime and wake times (Berger et al, 2008). Clinical sleep specialists (Buysse et al, 2006) have suggested that objective sleep indicators are more appropriate for assessing sleep disturbance. A sleep diary was recorded concurrently with the actigraph readings to confirm the exact bedtimes and wake times (Berger et al, 2008). The patients were asked to record the duration for which they took off the actigraph in the sleep diary to help the researcher define missing data and discard them. If the patients forgot to record it, the actigraphy analyst sought confirmation from the patients through the telephone. Data cleaning was performed before analyzing the actigraph data. Data processing and actigraph reading analysis were conducted by a researcher experienced in managing actigraph data (Littner et al, 2003).

Rest-activity rhythms. An actigraph was worn by the patients to collect data continuously for $72 \mathrm{~h}$ (Littner et al, 2003). Rest-activity rhythm parameters, namely $\mathrm{r} 24$ and $\mathrm{I}<\mathrm{O}$, were measured. All settings and analysis procedures were identical to those described in the Objective sleep quality subsection, except the data were exported to the Action 4 software (Ambulatory Monitoring) for analyzing rest-activity rhythms. $\mathrm{r} 24$ is a ratio that quantifies the regularity and consistency of activity between one day and the next day (Berger et al, 2012). The value of this indicator ranges from -1 to 1 , with a higher value representing more stable and regular rest-activity rhythms (Dowse and Ringo, 1989; Mormont et al, 2000). $\mathrm{I}<\mathrm{O}$ is the percentage of activity counts per minute when the patient is in bed, and it is lower than the median activity count when the patient is out of bed during the day (Minors et al, 1996). An analysis of $\mathrm{I}<\mathrm{O}$ requires the patient's sleep diary to validate the patient's bedtimes and wake times (Mormont et al, 2000), and the value of this indicator ranges from $0 \%$ to $100 \%$. A patient with high sleep quality at night and a high level of physical activity during the day will exhibit a prominent, strong circadian rhythm, and $\mathrm{I}<\mathrm{O}$ will be close to $100 \%$ (Mormont et al, 2000; Pati et al, 2007). Before commencing the study, the aforementioned researcher defined data as missing when a participant did not wear the actigraph for more than $1 \mathrm{~h}$ (Berger et al, 2008) and then discarded the missing data while analyzing r24.

Physical activity. Physical activity was assessed to determine contamination by the control group. Physical activity was assessed through actigraphy and by using the Bouchard 3-day physical activity record. The up activity mean was recorded through actigraphy during waking hours for $72 \mathrm{~h}$ continuously, along with rest-activity rhythms. The original physical activity record comprises activities recorded by the patient on two weekdays and one weekend day and is used to calculate energy expenditure (Bouchard et al, 1983). The 3-day physical activity record has been translated and adapted for Taiwanese culture (Lu et al, 2001). The reliability and validity of the adapted version was tested in Taiwan by using the TriTrac-R3D accelerometer. The results showed a satisfactory test-retest reliability and criterion-related validity of 0.95 and 0.81 , respectively. Although the 3 -day physical activity record is typically used to calculate daily energy expenditure (Bouchard et al, 1983), we used it to determine the physical activity minutes in the present study. After the patients completed recording the activities undertaken for 2 weekdays and 1 weekend day, we used the record to calculate the 3-day sum and mean minutes of light, moderate, and vigorous activities for each participant.

Statistical analyses and sample size calculations. According to the results of eight participants in the pilot study, the mean [standard deviation (SD)] PSQI scores of the walking exercise and usual-care groups were 7.25 (4.99) and 8.50 (4.51), respectively, after the 12-week home-based walking exercise program. The sample size was estimated to be 40 patients per group by using the $\mathrm{G}^{\star}$ Power software (Version 3.1.0; Faul et al, 2009) for repeated measures, with a significance level of 0.05 , effect size of 0.26 , power of 0.8 , and correlation of 0.8 . On the basis of an assumed dropout rate of $30 \%$, the enrollment of 104 patients was considered adequate.

We used an intention-to-treat approach for analysis. The $t$ test or chi-square test was used to determine the differences in the

Table 1. Demographic data and disease characteristics of all participants categorised into walking exercise and usual-care groups $(N=111)$

\begin{tabular}{|c|c|c|c|}
\hline & $\begin{array}{l}\text { Walking } \\
\text { exercise } \\
\text { group } \\
n=56\end{array}$ & $\begin{array}{l}\text { Usual-care } \\
\text { group } \\
n=55\end{array}$ & $P^{a}$ \\
\hline \multicolumn{4}{|l|}{ Age (years) } \\
\hline $\begin{array}{l}\text { Mean (SD) } \\
\text { Median } \\
\text { Range }\end{array}$ & $\begin{array}{c}64.64(11.54) \\
67.00 \\
37-83\end{array}$ & $\begin{array}{c}62.51(9.64) \\
62.00 \\
40-81\end{array}$ & 0.284 \\
\hline \multicolumn{4}{|l|}{ Education (years) } \\
\hline Mean (SD) & $10.71(4.77)$ & $10.71(4.45)$ & 0.995 \\
\hline \multicolumn{4}{|l|}{$\operatorname{Sex}(n, \%)$} \\
\hline $\begin{array}{l}\text { Male } \\
\text { Female }\end{array}$ & $\begin{array}{l}24(42.9) \\
32(57.1)\end{array}$ & $\begin{array}{l}25(45.5) \\
30(54.5)\end{array}$ & 0.783 \\
\hline \multicolumn{4}{|l|}{ Employed (n, \%) } \\
\hline $\begin{array}{l}\text { No } \\
\text { Yes }\end{array}$ & $\begin{array}{l}40(71.4) \\
16(28.6)\end{array}$ & $\begin{array}{l}31(56.4) \\
24(43.6)\end{array}$ & 0.988 \\
\hline \multicolumn{4}{|c|}{ Marital status (n, \%) } \\
\hline $\begin{array}{l}\text { Married } \\
\text { Unmarried }\end{array}$ & $\begin{array}{l}46(82.1) \\
10(17.9)\end{array}$ & $\begin{array}{l}45(81.8) \\
10(18.2)\end{array}$ & 0.965 \\
\hline \multicolumn{4}{|c|}{ Cancer stage $(n, \%)^{b}$} \\
\hline $\begin{array}{l}1 \\
2 \\
3 \\
4 \\
\text { Unknown }\end{array}$ & $\begin{aligned} 34 & (60.8) \\
5 & (8.9) \\
5 & (8.9) \\
5 & (8.9) \\
7 & (12.5)\end{aligned}$ & $\begin{aligned} 38 & (69.1) \\
4 & (7.3) \\
5 & (9.0) \\
4 & (7.3) \\
4 & (7.3)\end{aligned}$ & 0.355 \\
\hline \multicolumn{4}{|c|}{ Treatment status (n, \%) } \\
\hline $\begin{array}{l}\text { On treatment } \\
\text { Off treatment }\end{array}$ & $\begin{array}{l}37(66.1) \\
19(33.9)\end{array}$ & $\begin{array}{l}39(70.9) \\
16(29.1)\end{array}$ & 0.583 \\
\hline \multicolumn{4}{|c|}{ Current treatment $(\mathrm{n}, \%)^{\mathrm{c}}$} \\
\hline $\begin{array}{l}\text { Surgery } \\
\text { Radiotherapy } \\
\text { Target therapy } \\
\text { Chemoradiotherapy }\end{array}$ & $\begin{aligned} 30 & (81.1) \\
2 & (5.4) \\
3 & (8.1) \\
2 & (5.4)\end{aligned}$ & $\begin{aligned} 31 & (79.5) \\
2 & (5.1) \\
5 & (12.8) \\
1 & (2.6)\end{aligned}$ & 0.861 \\
\hline \multicolumn{4}{|c|}{ Days since diagnosis } \\
\hline $\begin{array}{l}\text { Mean (SD) } \\
\text { Median } \\
\text { Range }\end{array}$ & $\begin{array}{c}451.06(636.82) \\
103.50 \\
7-2493\end{array}$ & $\begin{array}{c}456.53(812.50) \\
112.00 \\
12-3465\end{array}$ & 0.969 \\
\hline \multicolumn{4}{|c|}{$\begin{array}{l}\mathbf{a}_{P} \text { values are based on the chi-square test for categorical variables and the } t \text { test for } \\
\text { continuous variables. } \\
\mathbf{b}_{\text {In the chi-square test, cancer stages } 2,3,4 \text {, and unknown were merged in one cell for }} \\
\text { comparison with cancer stage } 1 \text { to follow the statistical assumption and treat fewer than five } \\
\text { cells. We present data from each original cell here for clarity. } \\
c_{\text {In the chi-square test, radiotherapy, target therapy, and chemoradiotherapy were merged }} \\
\text { in one cell for comparison with surgery to follow the statistical assumption and treat fewer } \\
\text { than five cells. We present data from each original cell here for clarity. }\end{array}$} \\
\hline
\end{tabular}


baseline values between the two groups. We used a general linear model for evaluating the mean values, SDs, and differences between group outcomes at the baseline and 3 and 6 months after intervention. Generalised estimating equations (GEEs) were used for testing group differences with respect over time. A GEE model was used to test the moderating effect of the rest-activity rhythm indicators $(\mathrm{r} 24$ and $\mathrm{I}<\mathrm{O}$ ) on the subjective (PSQI) and objective (TST, SE, SOL, and WASO) indicators of sleep quality. All tests involved a two-sided significance level of $\alpha=0.05$. All statistical analyses were conducted using the IBM Statistical Package for the Social Sciences (version 20) for Windows (IBM, Somers, NY, USA).

\section{RESULTS}

Study population and baseline data. We recruited 111 patients with lung cancer, aged 37-88 years, between March 2010 and March 2015. The demographic data and disease characteristics of the walking exercise and routine care groups did not differ significantly $(P>0.2$ for all tests; Table 1$)$. Nevertheless, pretrial r24 and moderate-intensity physical activity minutes differed significantly between the two groups.

Protocol adherence. Among the 111 patients, 56 and 55 were randomly assigned to the walking exercise and rusual-care groups, respectively. Pretrial data and PSQI were collected for all participants; however, the actigraph data were missing for six participants because the participants forgot to wear the actigraph or the actigraph malfunctioned. After 6 months, 89 participants remained (80.2\%; Figure 1). Among all participants, 87 submitted measurements at all three collection time points (78.4\%) and 24 submitted measurements at only one or two collection time points $(21.6 \%)$. No significant difference was found between the walking exercise and usual-care groups in terms of completing the measurements. Thirteen participants in the walking exercise group $(23.2 \%)$ and nine in the usual-care group (16.4\%) dropped out of the study; this difference was not significant. The demographic factors, disease characteristics, and pretrial outcomes (PSQI, TST, SE, SOL, WASO, r24, and I $>$ O) of participants who submitted measurements at all three collection time points and participants who did not complete or withdrew from the study did not differ significantly; further analysis using Little's test of missing completely at random also showed that the results were nonsignificant $\left(\chi^{2}=380.17\right.$, $P=0.307)$.

The participants in the walking exercise group completed an average of 21 walking exercise sessions $(\mathrm{SD}=43.99)$. The median number of completed sessions was 24; 24 participants (42.9\%) completed all 36 scheduled exercise sessions within 3 months, whereas $31(55.4 \%)$ completed at least two or three of the exercise sessions. All participants completed an average of $58.2 \%$ sessions. Reasons for not completing all 36 sessions included dropping out from the study $(n=13)$, feeling unwell $(n=9)$, losing interest $(n=6)$, or being busy $(n=4)$.

In the walking exercise group, the mean amount of moderateintensity physical activity was $8 \mathrm{~min} /$ day at the baseline and 28 and $10 \mathrm{~min} /$ day at 3 and 6 months after intervention, respectively. In the usual-care group, the mean amount of moderate physical activity was $29 \mathrm{~min} /$ day at the baseline and 37 and $46 \mathrm{~min} /$ day at 3 and 6 months after intervention, respectively. We also noted that the interaction term group

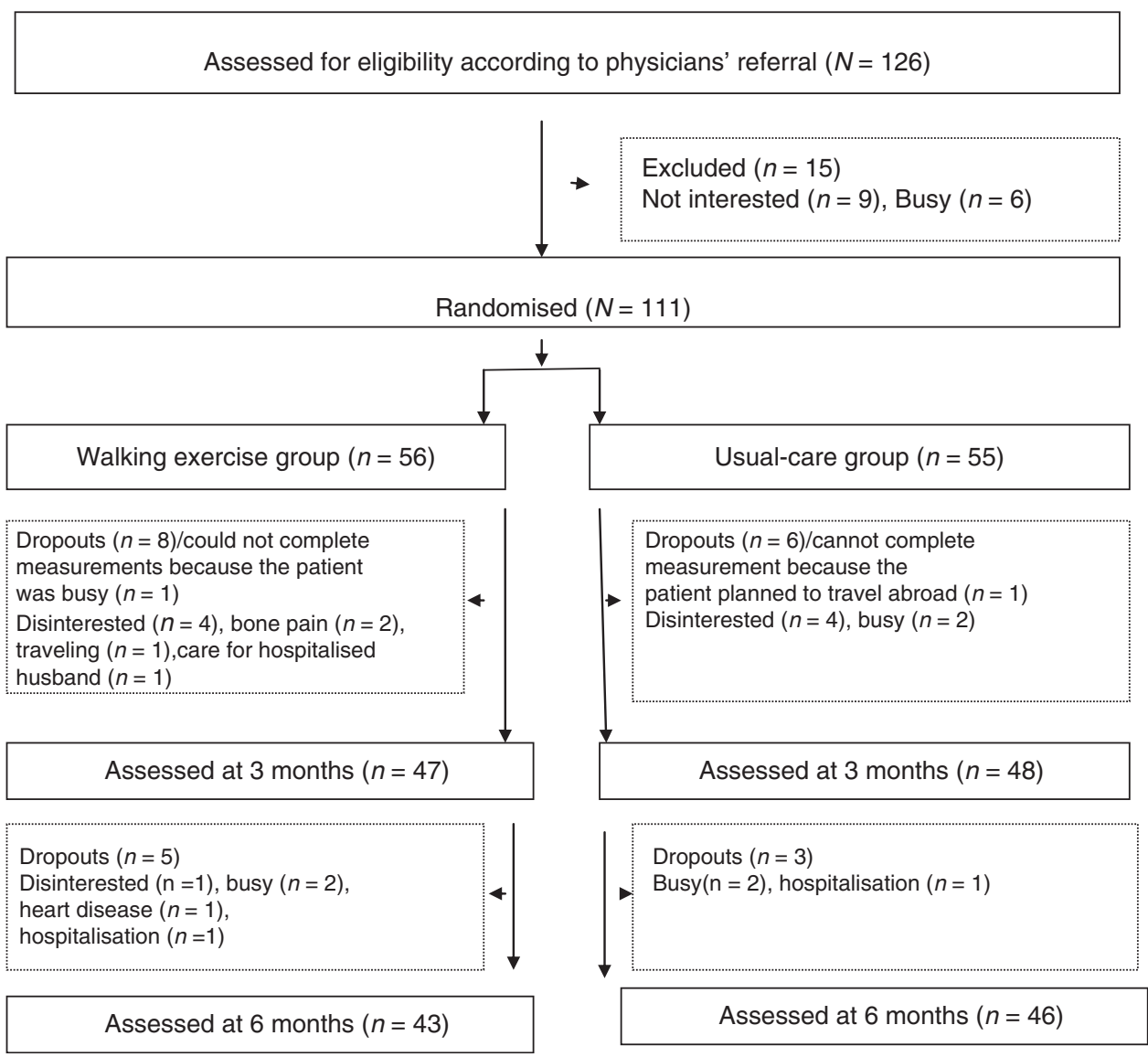

Figure 1. Consolidated standards of reporting trials (CONSORT) diagram showing the flow of participants through the trial. 
difference $\times$ time was not statistically significant in the GEE model (Wald $\chi^{2}=1.977, P=0.372$ ). In addition, through disclosures and the physical activity record data for the 3- and 6-month measures, we noted that in the usual-care group, three participants performed biking activities, two hiked, and one walked slowly, all for at least $1 \mathrm{~h}$ /day.

Effects of walking exercises on subjective and objective sleep quality and rest-activity rhythms. Because of the significant differences in the pretrial r24 and moderate-intensity physical activity minutes between the walking exercise and usual-care groups, these two variables were controlled using GEEs to analyze the effect of walking exercises on subjective and objective sleep quality and rest-activity rhythms. The walking exercise group had significantly improved subjective sleep quality (lower PSQI scores) compared with the usual-care group over time (Wald $\chi^{2}=15.16$, $P=0.001$; Table 2 and Figure 2). Nevertheless, although both groups scored $>5$ on the PSQI, indicating disturbed sleep, the walking exercise group had improved scores by 3 points, whereas the usual-care group showed no change in their sleep quality. In addition, the walking exercise group had significantly improved objective sleep quality (increased TST) compared with the usualcare group over time (Wald $\chi^{2}=7.59, P=0.023$; Table 2 and Figure 2), indicating that walking can effectively increase TST as well. These results demonstrated a significantly positive effect of walking exercises on the subjective and objective sleep quality of the patients with lung cancer.

No significant differences over time were observed for other indicators of objective sleep quality (SE, SOL, and WASO) and restactivity rhythms (r24 and I>O). However, SOL at 6 months after intervention was significantly lower in the walking exercise group than in the usual-care group ( $23 \mathrm{~min} v s 38 \mathrm{~min}, P=0.045$; Table 2).
We further analyzed the intervention effects of walking exercises on the PSQI, TST, SE, SOL, WASO, r24, and $\mathrm{I}<\mathrm{O}$, according to the clinical cutoff values (Coates et al, 1982; Buysse et al, 1989; Lacks and Morin, 1992; Espie et al, 2001; Savard and Morin, 2001). We observed no significant differences in the indicators of subjective sleep quality (PSQI), objective sleep quality (TST, SE, SOL, and WASO) and rest-activity rhythms (r24 and I>O) over time (Supplementary Table 2).

Moderating effects of rest-activity rhythms on subjective and objective sleep quality. The GEE model was used to examine the moderating effects of rest-activity rhythms on subjective and objective sleep quality. In the TST model, $\mathrm{I}<\mathrm{O}$ and group had a significant interaction effect $(\beta=3.70, P=0.032$; Supplementary Table 1), thus indicating that walking exercises may amplify or diminish the objective sleep indicator TST depending on $\mathrm{I}<\mathrm{O}$ of different rest-activity rhythms. Furthermore, in the PSQI model, $\mathrm{I}<\mathrm{O}$ and group had a nearly significant interaction effect $(\beta=-0.13, P=0.050$; Supplementary Table 1$)$. To comprehensively understand the beneficial effects of walking exercises on patients on the basis of their rest-activity rhythms, we classified r24 and $\mathrm{I}<\mathrm{O}$ as low, average, or high depending on their percentiles (Mormont et al, 2000). Walking exercises significantly improved subjective sleep quality (reduced PSQI scores) and objective sleep quality (increased TST) over time in the walking exercise group with poor rest-activity rhythm of $\mathrm{r} 24(\leqslant 0.30)$, and this effect was more evident in the walking exercise group than in the usual-care group. In the GEE model, after adjustment for the significant differences in $\mathrm{I}<\mathrm{O}$ between the walking exercise and usual-care groups, the interaction term group difference $\times$ time was statistically significant (PSQI: Wald $\chi^{2}=9.33, P=0.009$; TST: Wald $\chi^{2}=9.44, P=0.009$; Table 3 and Figure 3 ); group difference $\times$ time

Table 2. Per-protocol analysis: means, s.d., and differences between groups in outcomes over time according to generalised estimating equations adjusted for baseline r24 and moderate-intensity physical activity minutes $(N=111)$

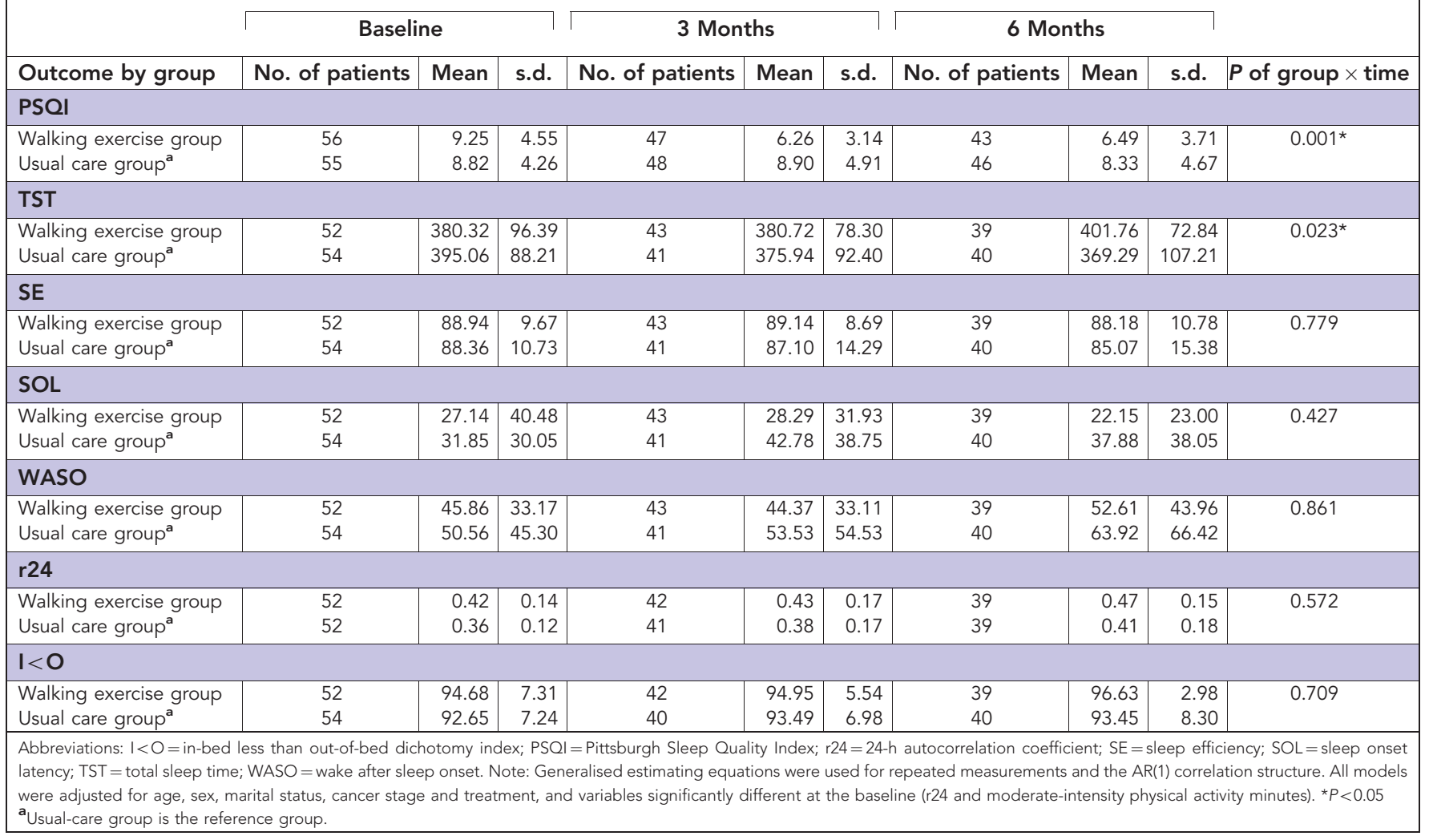



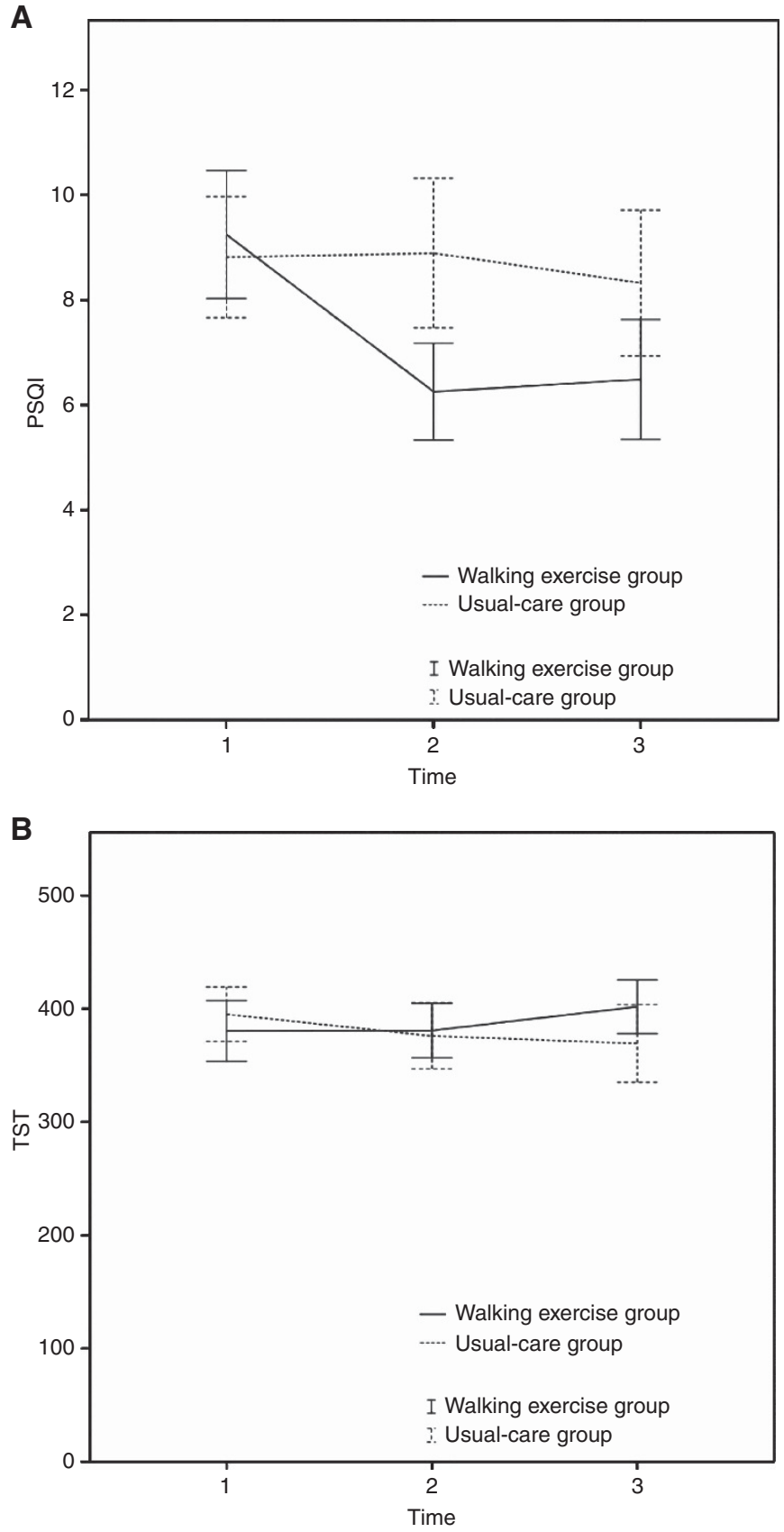

Figure 2. Effects of walking exercise on subjective and objective sleep quality in both groups. (A) PSQI scores decreased and (B) TST increased in the walking exercise group over time. PSQI, Pittsburgh Sleep Quality Index; TST, total sleep time.

was not significant (Table 3) compared with that of participants with favorable r24 $(\geqslant 0.46)$.

Walking exercises significantly improved subjective sleep quality (reduced PSQI scores) over time in the walking exercise group participants with poor rest-activity rhythm of $\mathrm{I}<\mathrm{O}(\leqslant 96.93)$, and this effect was more prominent in the walking exercise group than in the usual-care group. In the GEE model, after adjustment for the significant differences in PSQI scores between the walking exercise and usual-care groups, the interaction term group difference $\times$ time became significant (Wald $\chi^{2}=30.84, P<0.0001$ ). In addition, walking exercises slightly improved objective sleep quality (increased TST) over time for the walking exercise group participants with poor rest-activity rhythm of $\mathrm{I}<\mathrm{O}(\leqslant 96.93)$, and this effect was more prominent in the walking exercise group than in the usual-care group. In the GEE model, after adjustment for the significant differences in PSQI scores between the walking exercise and usual-care groups, the interaction term group difference $\times$ time was nearly significant (Wald $\chi^{2}=5.44$, $P<0.066$ ) but remained nonsignificant (Table 3) compared with that of participants with favorable $\mathrm{I}>\mathrm{O}(\geqslant 97.35)$. For further examination, we considered 0.42 and $97 \%$ to be cutoff values for r24 and $\mathrm{I}<\mathrm{O}$, respectively (Mormont et al, 2000). Walking exercises still significantly improved subjective sleep quality (reduced PSQI scores) and objective sleep quality (increased TST) over time in the walking exercise group with poor r24 $(\leqslant 0.42)$ and poor $\mathrm{I}<\mathrm{O}$ ( $\leqslant 97$; Supplementary Table 3$)$. Thus, walking exercises more effectively improved the subjective and objective sleep quality — as assessed using PSQI scores and TST_-of lung cancer patients with poor rest-activity rhythms than of those with favorable rest-activity rhythms.

Adverse events. During the study period, one participant in the walking exercise group was hospitalised for shortness of breath and hematuria; nevertheless, the walking exercises were eliminated as the cause. In addition, one participant in the usual-care group was hospitalised for an altered state of consciousness caused by brain metastasis.

\section{DISCUSSION}

This study is the first to verify that home-based walking exercises can improve the subjective and objective sleep quality and restactivity rhythms of patients with lung cancer. This finding is similar to that of previous studies on patients with colorectal, breast, and other types of cancer (Young-McCaughan et al, 2003; Rabin et al, 2009), indicating that the effect of exercise on improving sleep quality among patients with lung cancer is similar to that among patients with other cancers. However, we observed that the exercises did not stabilise rest-activity rhythms. This result is similar to that of a small-scale study on healthy adults, which reported that a 4-day short-term regimen of moderate-intensity stationary bicycle exercises induced phase-advance shifts but did not affect the circadian rhythm of plasma melatonin levels (Yamanaka et al, 2010). Additional studies are required to determine whether exercise interventions conducted for a longer duration (e.g., $\geqslant 3$ months) or at a specific time of day alter or adjust rest-activity rhythms. In the present study, the overall effects of the exercise intervention on rest-activity rhythms in 111 participants were nonsignificant. However, independent analyses of groups of participants with poor rest-activity rhythms, that is, those with poor $\mathrm{r} 24$ or $\mathrm{I}<\mathrm{O}$, showed that exercise significantly improved both PSQI scores and TST, thus confirming that exercise can improve and maintain improvements in subjective and objective sleep quality of lung cancer patients with poor restactivity rhythms.

The results of the present study support another initial assumption that circadian rhythms have a moderating effect on the subjective and objective sleep quality of patients with lung cancer. The results showed that walking exercises more effectively improved the subjective and objective sleep quality of lung cancer patients with poor rest-activity rhythms, as assessed using the PSQI and TST. For example, in the walking exercise group, PSQI scores significantly decreased by 4.27 points (from 12.27 points at the baseline to 8.0 points at 6 months) in the poor $\mathrm{I}<\mathrm{O}$ subgroup $(\mathrm{I}<\mathrm{O}$ value $\leqslant 93.96)$ and by only 2.87 points (from 7.82 points at the baseline to 4.95 points at 6 months $)$ in the favorable $\mathrm{I}<\mathrm{O}$ subgroup $(\mathrm{I}<\mathrm{O}$ value $\geqslant 97.35$; Table 3 ). Furthermore, in the walking exercise group, the TST value significantly increased by $40.84 \mathrm{~min}$ (from 
Table 3. Subgroups of rest-activity rhythm analysis: Means, standard deviations, and differences between groups in outcomes over time according to generalised estimating equations

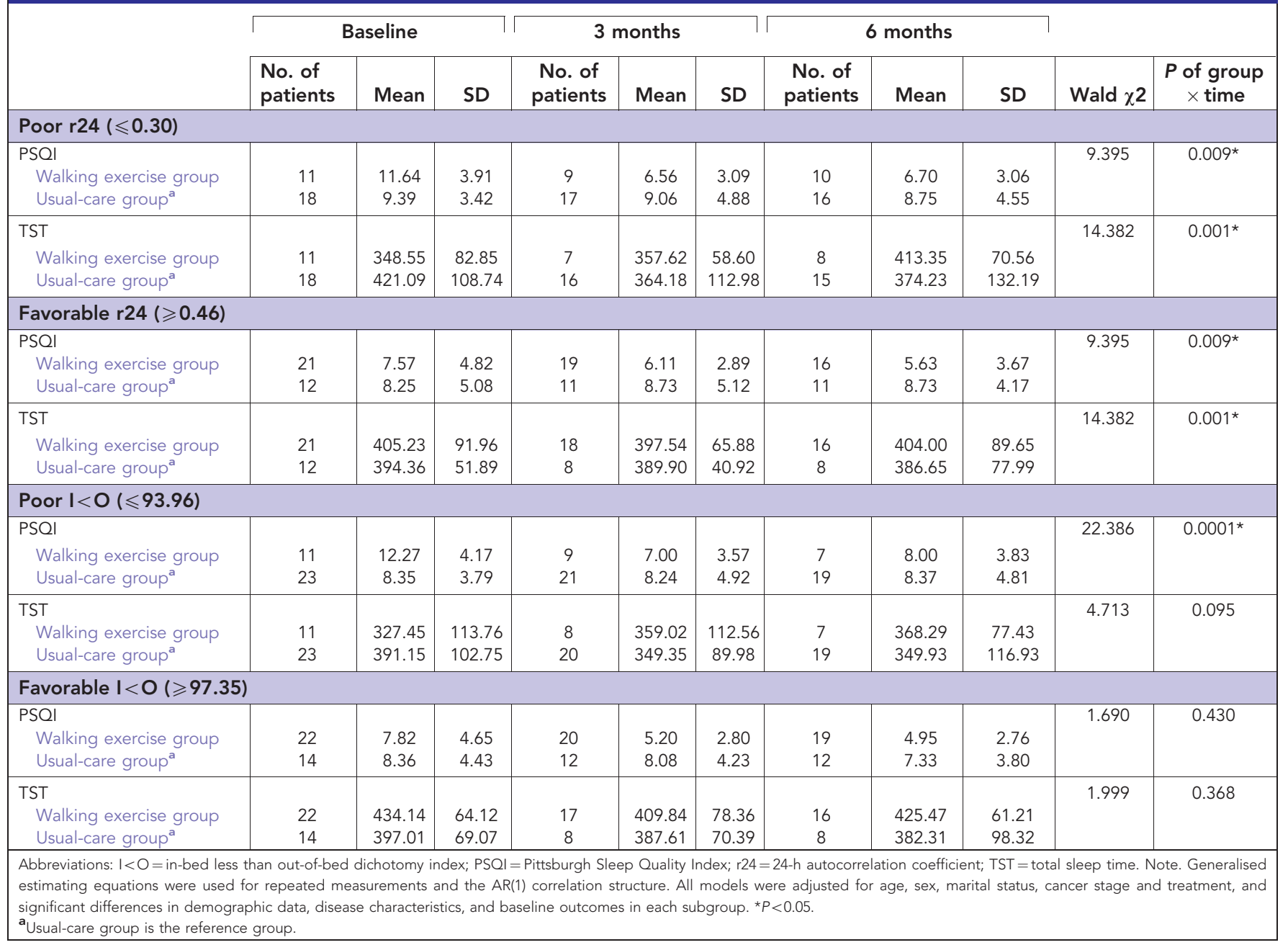

$327.45 \mathrm{~min}$ at the baseline to $368.29 \mathrm{~min}$ at 6 months) in the poor $\mathrm{I}<\mathrm{O}$ subgroup $(\mathrm{I}<\mathrm{O}$ value $\leqslant 93.96)$ and decreased by $8.67 \mathrm{~min}$ (from $434.14 \mathrm{~min}$ at the baseline to $425.47 \mathrm{~min}$ at 6 months) in the favorable $\mathrm{I}<\mathrm{O}$ subgroup $(\mathrm{I}<\mathrm{O}$ value $\geqslant 97.35$; Table 3 ). This suggests that rest-activity rhythms may be involved in poor sleep quality. Studies have reported that the amplitude of rest-activity rhythms and indicators of subjective and objective sleep quality (e.g., TST and SE) are negatively correlated; in other words, people with unstable or unapparent rest-activity rhythms exhibit poor sleep quality (Berger et al, 2007). We recommend that future intervention studies include rest-activity rhythms as moderating variables. In addition, examining the rest-activity rhythm indicators $\mathrm{r} 24$ and $\mathrm{I}<\mathrm{O}$ may provide a clearer understanding of a patient's overall sleep quality.

Although we performed randomisation in our study, the mean amount of moderate-intensity physical activity in the usual-care group still higher than the walking exercise group. We discovered, through their disclosure or 3-d PAR, that 3 participants in the usual-care group biked for at least one hour per day, 2 participants hiked at least one hour per day, and one participant walked slowly for at least one hour per day. The research ethics prohibited us from limiting the activities of the participants in the usual-care group. In particular, patients with lung cancer who have experienced the struggle between life and death have a strong desire for maintaining a healthy lifestyle and aspire to become ardent pursuers of better health. Studies have reported that patients often adjust their lifestyles after receiving a diagnosis of cancer and during cancer treatment. They are particularly likely to increase physical activity to alleviate their illness or improve their overall health (Mustian et al, 2006). This difference between the two groups on the mean amount of moderate-intensity physical activity can be attributed to the small sample size.

The present study has some limitations. First, we could not perform a blind study. The patients were informed regarding the exercise regimen; thus, patients may have experienced the placebo effect, leading to observation bias. To reduce the risk of observation bias, a standardised procedure, conducted by the same personnel with the same equipment and interview guide for data collection, should be devised. In addition, telephone counseling for the usualcare group similar to that received by the walking exercise group (such as weekly nutrition counseling) should have been performed, because they would have reduced the risk of the placebo effect in the walking exercise group caused by a difference in the number of counseling telephone calls received. Second, because of the time limit, we only concluded that 12 weeks of exercise causes a nonsignificant effect on rest-activity rhythms. We suggest that future studies should employ a longer period for exercise training. Third, three participants in the usual-care group performed exercise activities, which may have led to an underestimation of the effect of the exercise intervention. Fourth, contamination in the usual-care group may exist in this study. 
A

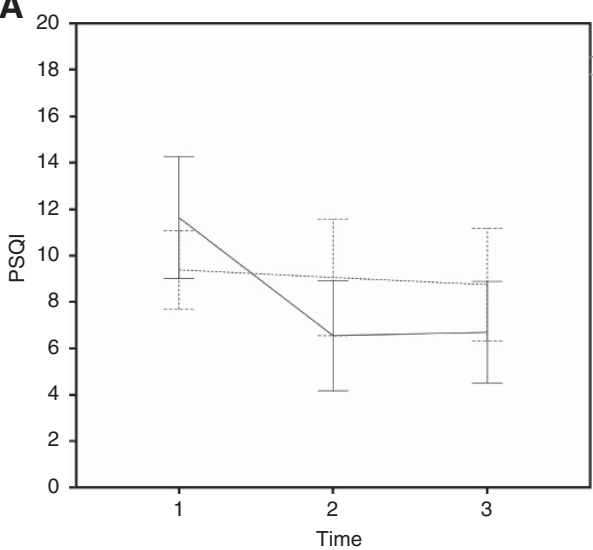

B

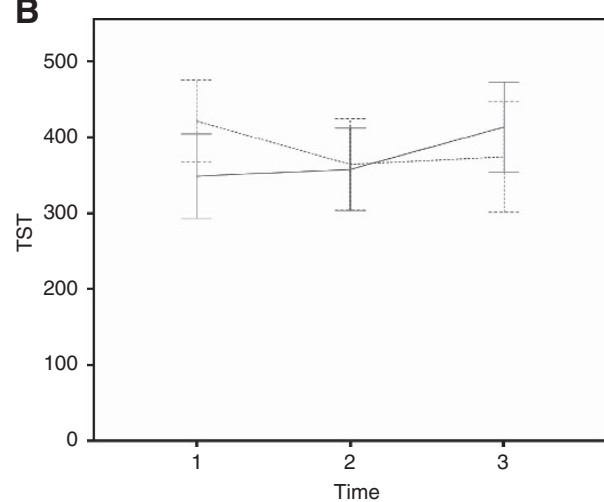

C Subgroup of poor r 24 Walking exercise group
Usual-care group Walking exercise group Usual-care group

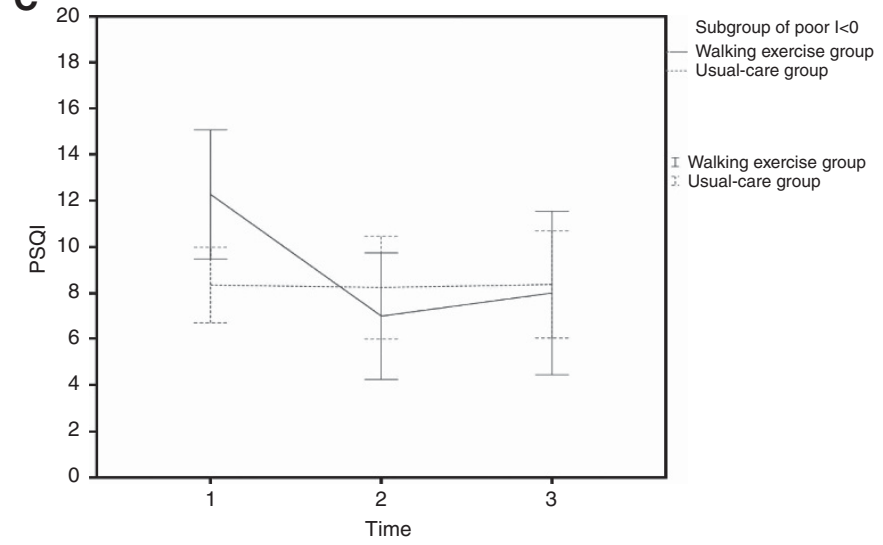

Subgroup of poor r24 Walking exercise group
Usual-care group

D Walking exercise group Usual-care group

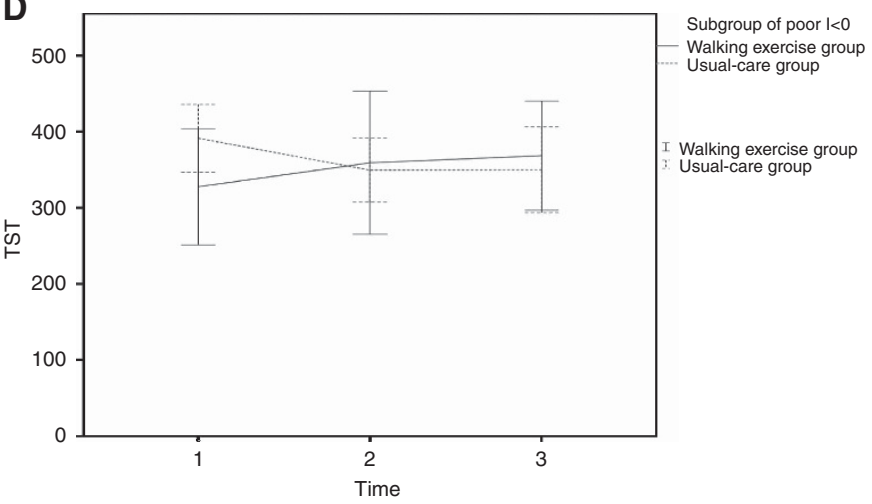

Figure 3. Subjective and objective sleep quality in the $r 24$ and $I<0$ subgroups. The trends of changes in (A) the PSQI and (B) TST in the poor $r 24$ subgroup and in (C) the PSOI and (D) TST in the poor I<O subgroup. I<O, in-bed less than out-of-bed dichotomy index; PSQI, Pittsburgh Sleep Quality Index; r24, 24-h autocorrelation coefficient; TST, total sleep time.

In summary, the present study was the first to verify that a regimen of home-based walking exercises is an effective intervention for patients with lung cancer. The study results demonstrated that home-based walking exercises can effectively improve the subjective and objective sleep quality of patients with lung cancer, particularly those with poor rest-activity rhythms. Healthcare providers should recognise the benefits of exercise and incorporate it as a key component of lung cancer care and rehabilitation.

\section{ACKNOWLEDGEMENTS}

The authors thank all study participants. This study was supported by grants 104ntunhs-NT-02 and NSC102-2628-B-038-007-MY3(3/3). Trial Registry: www.chictr.org; Identifier: ChiCTR-TRC-14004756

\section{CONFLICT OF INTEREST}

The authors declare no conflict of interest.

\section{REFERENCES}

Baiden P, Fallon B, den Dunnen W, Boateng GO (2015) The enduring effects of early-childhood adversities and troubled sleep among Canadian adults: a population-based study. Sleep Med 16(6): 760-767.

Berger AM, Farr LA, Kuhn BR, Fischer P, Agrawal S (2007) Values of sleep/ wake, activity/rest, circadian rhythms, and fatigue prior to adjuvant breast cancer chemotherapy. J Pain Symptom Manage 33(4): 398-409.
Berger AM, Hertzog M, Geary CR, Fischer P, Farr L (2012) Circadian rhythms, symptoms, physical functioning, and body mass index in breast cancer survivors. J Cancer Surviv 6(3): 305-314.

Berger AM, Wielgus KK, Young-McCaughan S, Fischer P, Farr L, Lee KA (2008) Methodological challenges when using actigraphy in research. J Pain Symptom Manage 36(2): 191-199.

Borg G (1998) Borg's Perceived Exertion and Pain Scales. Human Kinetics: Champaign, IL.

Bouchard C, Tremblay A, Leblanc C, Lortie G, Savard R, Thériault G (1983) A method to assess energy expenditure in children and adults. Am J Clin Nutr 37(3): 461-467.

Buysse DJ, Ancoli-Israel S, Edinger JD, Lichstein KL, Morin CM (2006) Recommendations for a standard research assessment of insomnia. Sleep 29(9): 1155-1173.

Buysse DJ, Reynolds CF, Monk TH, Berman SR, Kupfer DJ (1989) The Pittsburgh Sleep Quality Index: a new instrument for psychiatric practice and research. Psychiatry Res 28(2): 193-213

Chen HM, Tsai CM, Wu YC, Lin KC, Lin CC (2015a) Randomised controlled trial on the effectiveness of home-based walking exercise on anxiety, depression and cancer-related symptoms in patients with lung cancer. Br J Cancer 112(3): 438-445.

Chen HM, Wu YC, Tsai CM, Tzeng JI, Lin CC (2015b) Relationships of circadian rhythms and physical activity with objective sleep parameters in lung cancer patients. Cancer Nurs 38(3): 215-223.

Chen ML, Yu CT, Yang CH (2008) Sleep disturbances and quality of life in lung cancer patients undergoing chemotherapy. Lung Cancer 62(3): 391-400.

Cheville AL, Kollasch J, Vandenberg J, Shen T, Grothey A, Gamble G, Basford JR (2012) A home-based exercise program to improve function, fatigue, and sleep quality in patients with stage IV lung and colorectal cancer: a randomized controlled trial. J Pain Symptom Manage 45(5): 811-821.

Coates TJ, Killen JD, George J, Marchini E, Silverman S, Thoresen C (1982) Estimating sleep parameters: a multitrait-multimethod analysis. J Consult Clin Psychol 50(3): 345-352. 
Coleman EA, Goodwin JA, Kennedy R, Coon SK, Richards K, Enderlin C, Stewart CB, McNatt P, Lockhart K, Anaissie EJ (2012) Effects of exercise on fatigue, sleep, and performance: a randomized trial. Oncol Nurs Forum 39(5): 468-477.

de Souza L, Benedito-Silva AA, Pires ML, Poyares D, Tufik S, Calil HM (2003) Further validation of actigraphy for sleep studies. Sleep 26(1): 81-85.

Dowse HB, Ringo JM (1989) The search for hidden periodicities in biological time series revisited. J Theor Biol 139(4): 487-515.

Espie CA, Inglis SJ, Harvey L (2001) Predicting clinically significant response to cognitive behavior therapy for chronic insomnia in general medical practice: analysis of outcome data at 12 months posttreatment. J Consult Clin Psychol 69(1): 58-66.

Faul F, Erdfelder E, Buchner A, Lang AG (2009) Statistical power analyses using $\mathrm{G}^{*}$ Power 3.1: tests for correlation and regression analyses. Behav Res Methods 41(4): 1149-1160.

Gooneratne NS, Dean GE, Rogers AE, Nkwuo JE, Coyne JC, Kaiser LR (2007) Sleep and quality of life in long-term lung cancer survivors. Lung Cancer 58(3): 403-410.

Karvonen MJ, Kentala E, Mustala O (1957) The effects of training on heart rate: a longitudinal study. Ann Med Exp Biol Fenn 35(3): 307-315.

Kim K, Uchiyama M, Okawa M, Liu X, Ogihara R (2000) An epidemiological study of insomnia among the Japanese general population. Sleep 23(1): 41-47.

Lacks P, Morin CM (1992) Recent advances in the assessment and treatment of insomnia. J Consult Clin Psychol 60(4): 586-594.

Levin RD, Daehler MA, Grutsch JF, Quiton J, Lis CG, Peterson C, Gupta D, Watson K, Layer D, Huff-Adams S, Desai B, Sharma P, Wallam M, Delioukina M, Ball P, Bryant M, Ashford M, Copeland D, Ohmori M, Wood PA, Hrushesky WJ (2005) Circadian function in patients with advanced non-small-cell lung cancer. Br J Cancer 93(11): 1202-1208.

Littner M, Kushida CA, Anderson WM, Bailey D, Berry RB, Davila DG, Hirshkowitz M, Kapen S, Kramer M, Loube D, Wise M, Johnson SF (2003) Practice parameters for the role of actigraphy in the study of sleep and circadian rhythms: an update for 2002. Sleep 26(3): 337-341.

Lu CM, Lin SL, Huang YC, Lee MH, Wang SF (2001) A study on validity and reliability of self-report measures of physical activity-Using TriTrac-R3D accelerometer as criterion. J Health Educ (Chinese) 15: 99-114.

Miaskowski C, Lee KA (1999) Pain, fatigue, and sleep disturbances in oncology outpatients receiving radiation therapy for bone metastasis: a pilot study. J Pain Symptom Manage 17(5): 320-332.

Ministry of Health and Welfare (2013) Taiwan Cancer registry annual report, 2010. Retrieved 2014/7/7, from http://www.hpa.gov.tw/BHPNet/Web/Stat/ StatisticsShow.aspx?No=201305060001.

Minors D, Akerstedt T, Atkinson G, Dahlitz M, Folkard S, Levi F, Mormont C, Parkes D, Waterhouse J (1996) The difference between activity when in bed and out of bed. I. Healthy subjects and selected patients. Chronobiol Int 13(1): 27-34.
Mormont MC, Waterhouse J, Bleuzen P, Giacchetti S, Jami A, Bogdan A, Lellouch J, Misset JL, Touitou Y, Lévi F (2000) Marked 24-h rest/activity rhythms are associated with better quality of life, better response, and longer survival in patients with metastatic colorectal cancer and good performance status. Clin Cancer Res 6(8): 3038-3045.

Mustian KM, Griggs JJ, Morrow GR, McTiernan A, Roscoe JA, Bole CW, Atkins JN, Issell BF (2006) Exercise and side effects among 749 patients during and after treatment for cancer: a University of Rochester Cancer Center Community Clinical Oncology Program Study. Support Care Cancer 14(7): 732-741.

Pati AK, Parganiha A, Kar A, Soni R, Roy S, Choudhary V (2007) Alterations of the characteristics of the circadian rest-activity rhythm of cancer inpatients. Chronobiol Int 24(6): 1179-1197.

Rabin C, Pinto B, Dunsiger S, Nash J, Trask P (2009) Exercise and relaxation intervention for breast cancer survivors: feasibiity acceptabiity and effects. Psychooncology 18(3): 258-266.

Roscoe JA, Kaufman ME, Matteson-Rusby SE, Palesh OG, Ryan JL, Kohli S, Perlis ML, Morrowab GR (2007) Cancer-related fatigue and sleep disorders. Oncologist 12(suppl 1): 35-42.

Savard J, Morin CM (2001) Insomnia in the context of cancer: a review of a neglected problem. J Clin Oncol 19(3): 895-908.

Siegel R, Naishadham D, Jemal A (2013) Cancer statistics, 2013. CA Cancer J Clin 63(1): 11-30.

Tzeng JI, Fu YW, Lin CC (2012) Validity and reliability of the Taiwanese version of the Pittsburgh Sleep Quality Index in cancer patients. Int J Nurs Stud 49(1): 102-108.

Wang SY, Tsai CM, Chen BC, Lin CH, Lin CC (2008) Symptom clusters and relationships to symptom interference with daily life in Taiwanese lung cancer patients. J Pain Symptom Manage 35(3): 258-266.

Yamanaka Y, Hashimoto S, Tanahashi Y, Nishide SY, Honma S, Honma K (2010) Physical exercise accelerates reentrainment of human sleep-wake cycle but not of plasma melatonin rhythm to 8 -h phase-advanced sleep schedule. Am J Physiol Regul Integr Comp Physiol 298(3): R681-R691.

Young-McCaughan S, Mays MZ, Arzola SM, Yoder LH, Dramiga SA, Leclerc KM, Caton JR, Sheffler RL, Nowlin MU (2003) Research and commentary: change in exercise tolerance, activity and sleep patterns, and quality of life in patients with cancer participating in a structured exercise program. Oncol Nurs Forum 30(3): 441-454.

This work is published under the standard license to publish agreement. After 12 months the work will become freely available and the license terms will switch to a Creative Commons AttributionNonCommercial-Share Alike 4.0 Unported License.

Supplementary Information accompanies this paper on British Journal of Cancer website (http://www.nature.com/bjc) 